\title{
Research Paper \\ The Effectiveness of Mindfulness Based Cognitive Therapy on Self-Control and Academic Performance of Students with High/Low Level of Test Anxiety
}

\author{
Esmaeil Saadipour ${ }^{1}$, Hadaya Soltanizadeh $^{* 2}$, Fariborz Dortaj ${ }^{1}$ \\ 1. Professor, Department of Educational Psychology, Faculty of Psychology and Educational Sciences, Allameh Tabataba'i \\ University, Tehran, Iran
}

2. M.A. Student of Educational Psychology, Faculty of Psychology and Educational Sciences, Allameh Tabataba'i University, Tehran, Iran

Citation: Saadipour E, Soltanizadeh H, Dortaj F. The effectiveness of mindfulness based cognitive therapy on self-control and academic performance of students with high/low level of test anxiety. Quarterly Journal of Child Mental Health. 2020; 7(2): 183-194.

\section{http://dx.doi.org/10.29252/jcmh.7.2.16}

\section{A R T I C L E I N F O}

\section{Keywords:}

Mindfulness,

self-control, academic performance, test anxiety

Received: 20 Apr 2018

Accepted: 12 Aug 2018

Available: 21 Sep 2020

\section{A B S T R A C T}

Background and Purpose: As students form the cornerstone of educational systems, features and variables related to their mental health should be considered carefully. Research has shown that selfcontrol and academic performance are important factors related to the level of anxiety in students. This study aimed to investigate the effectiveness of cognitive therapy based on mindfulness on selfcontrol and academic performance of students with the moderating role of test anxiety.

Method: This research was a quasi-experimental study with pretest-posttest design, which had two control groups and two experimental groups. The study population included all the grade 6 female students in Sari in 2017. A sample of 40 students was selected by multi-stage cluster sampling and then was randomly divided into 20 students in experimental groups (10 students in high level of test anxiety, 10 students in low level of test anxiety), and 20 students in control group (10 students in high level of test anxiety, and 10 students in low level of test anxiety). The study tools included Selfcontrol Scale (Tangney, 2004), Academic Performance Questionnaire (Pham \& Taylor, 1999), and Test Anxiety Inventory (Spielberger, 2010). The experimental groups received eight 45-min sessions of mindfulness training, while the control groups underwent no intervention. Data were analyzed by multivariate ANCOVA.

Results: Findings of the research showed that cognitive therapy based on mindfulness was effective on the self-control of students with high level of test anxiety $(\mathrm{F}=41.07, \mathrm{P}<0.001)$, but it had no effect on the self-control of students with low level of test anxiety $(\mathrm{F}=0.06, \mathrm{P}>0.80)$. Also, this intervention was effective on the academic performance of students with high level of test anxiety $(\mathrm{P}<0.001$, $\mathrm{F}=28.64$ ), but it had no effect on the academic performance of students with low level of test anxiety $(\mathrm{F}=0.3, \mathrm{P}>0.68)$.

Conclusion: Based on the results of this study, it can be concluded that test anxiety has a moderating role in the effectiveness of mindfulness training on self-control and academic performance of students. Therefore, test anxiety must be emphasized as a factor influencing the effectiveness of mindfulness training on the self-control and academic performance of students.

\footnotetext{
* Corresponding author: Hadaya Soltanizadeh, Professor, M.A. Student of Educational Psychology, Faculty of Psychology and Educational Sciences, Allameh Tabataba'i University, Tehran, Iran.

E-mail addresses: Ha.sultanizadeh@gmail.com
} 


\title{
اثربخشى شناختدرمانى مبتنى بر ذهن آكاهى بر خودمهار كرى و عملكرد تحصيلى دانش آموزان با سطح اضطر اب امتحان بالا و بإيين براين
}

\author{
اسماعيل سعدى ثور'، هدايا سلطانىزاده*”'، فريبرز درتاج'

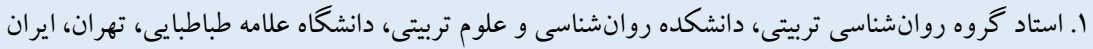

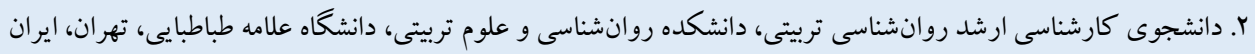

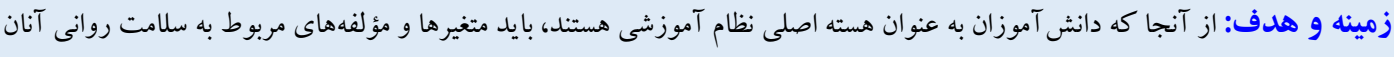

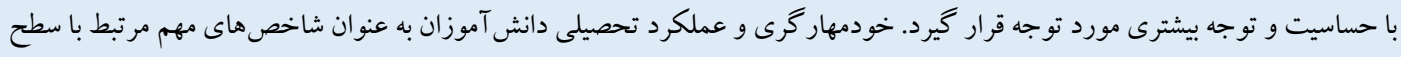

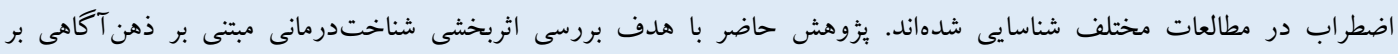

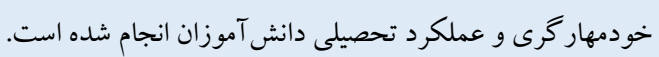

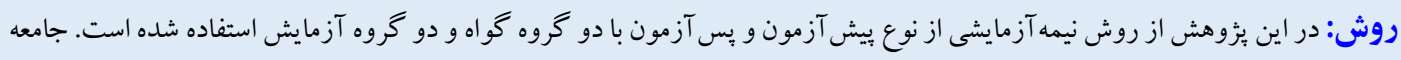
مشخصات مقاله

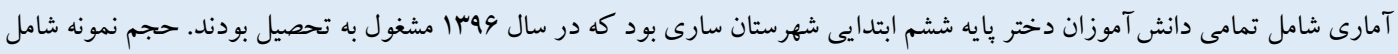

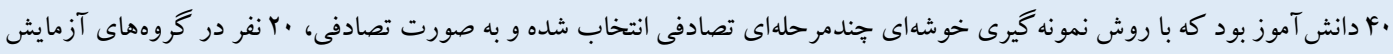

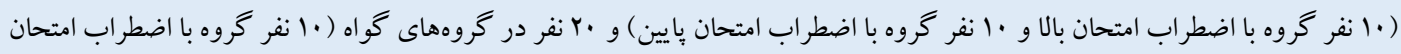

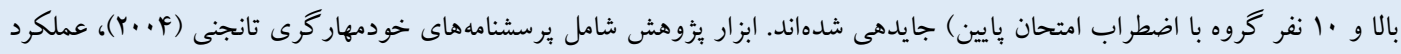

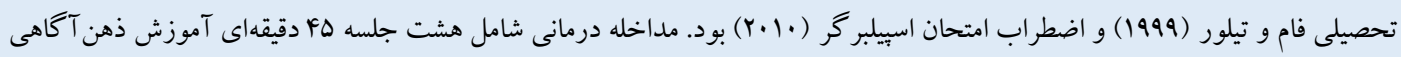

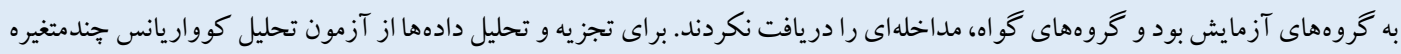
دوراهه استفاده شد.

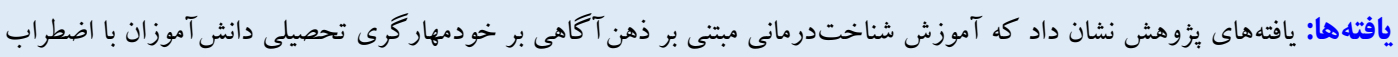

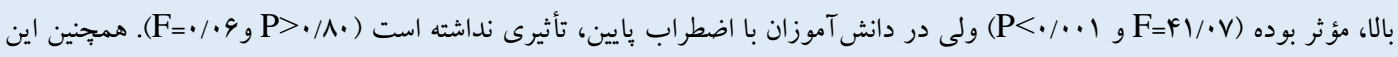

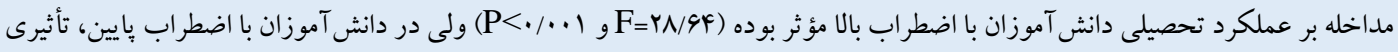

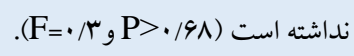

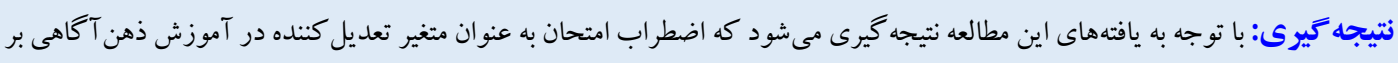

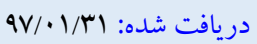

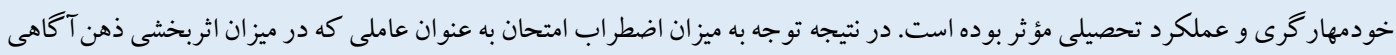

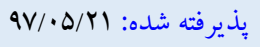

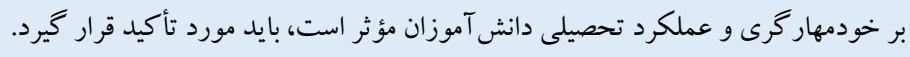

* نويسنده مسئول: هدايا سلطانى اده، دانشجوى كارشناسى ارشد روانشناسى تريتى، دانشكده روانشناسى و علوم تربيتى، دانشكاه علامه طباطبايى، تهران، ايران.

Ha.sultanizadeh@gmail.com رايانامه:....

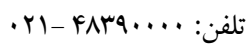


زمـان مطـالعه و جـه در زمان آزمون، بإيين تر از حد توان و دانش واقعى

مقدمه

آنها اسـت ( • (1). يُزوهش ناظمى، عسـكريان و كوهى وردهـكردى (11)

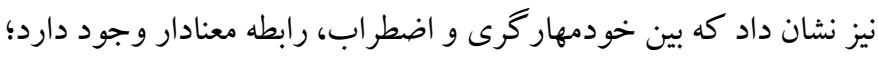

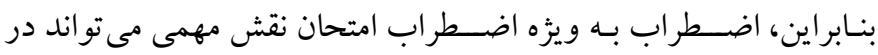

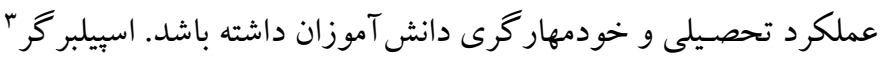

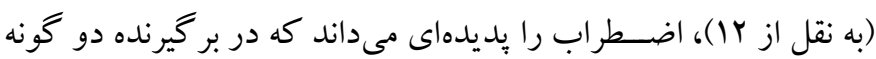

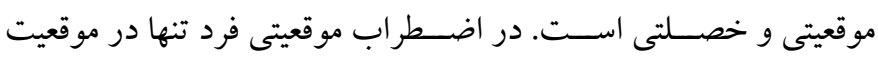

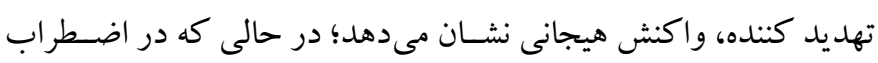

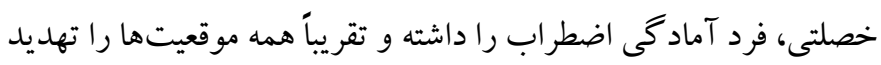
كنتـده ارزيابى مى كند. اضطراب امتحان نوعى خوداشتغالى ذهنى است

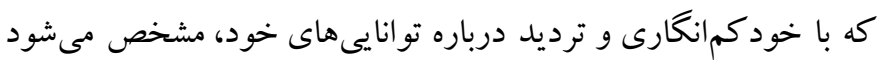

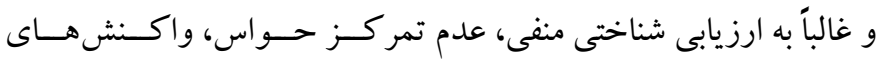

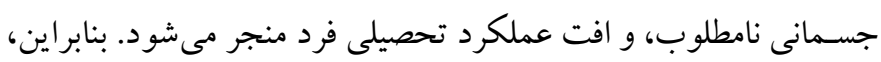

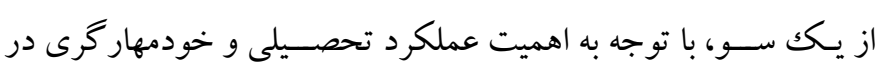

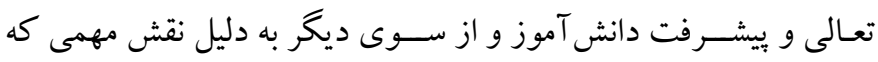

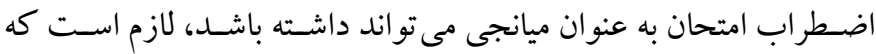

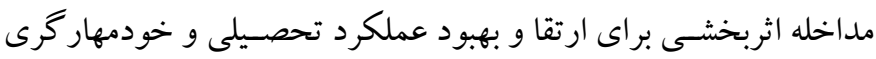
دانش آموزان انجام شود. يكى از مداخلات درمانى كه در جُند سال اخير كارايى آن در درمان

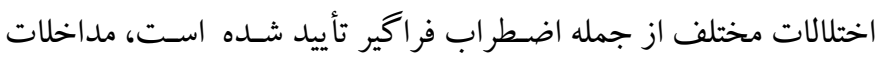

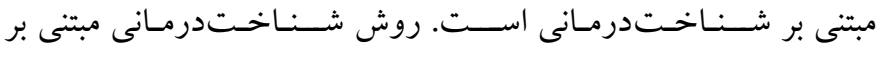

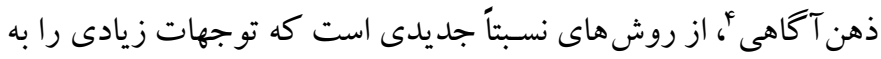

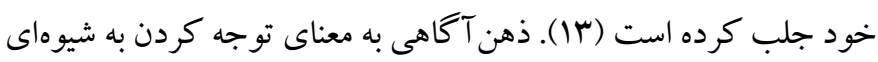

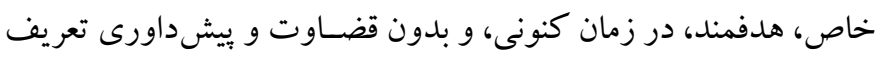

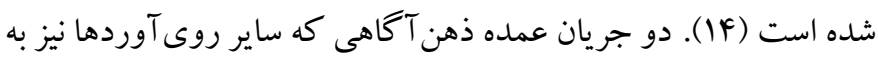

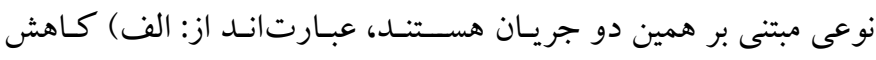

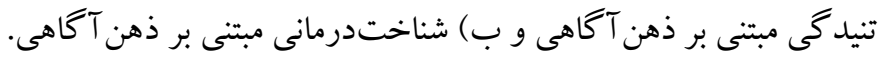

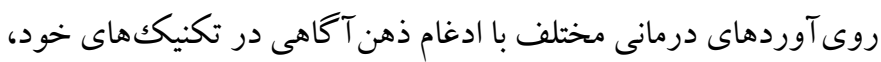

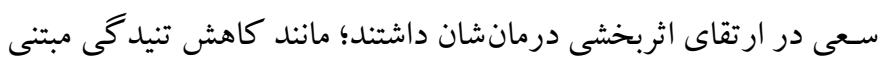

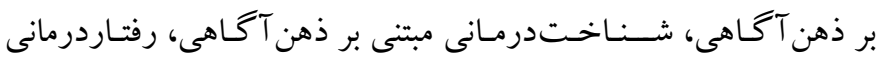

امروزه سازمانهاى آموزشى از مهم ترين نظامهاى اجتماعى در هر جامعه

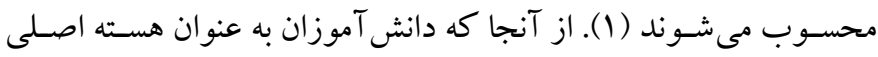

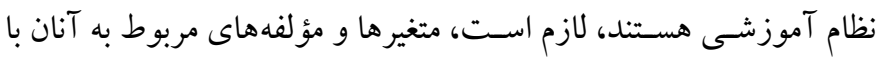

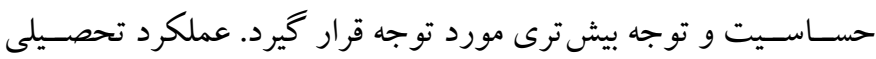

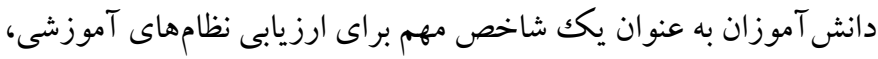

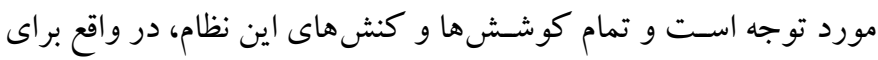
جامه عمل يوشاندن به اين موضوع است (Y). عملكرد تحصيلى به عنوان

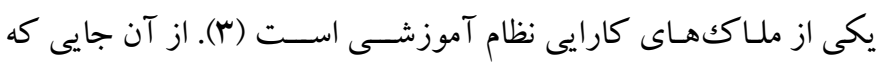

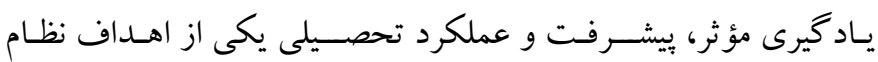

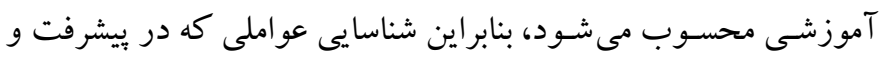

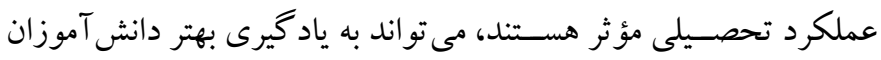

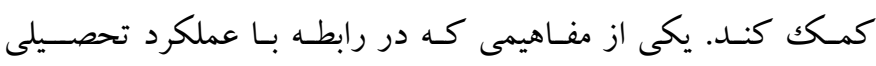

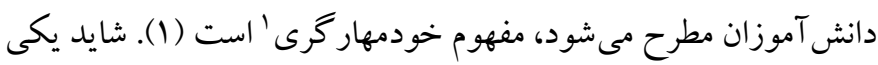

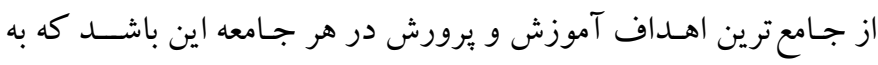
دانش آموزان آموزش داده شـود تا مسـئوليت اعمال خود را بيذيرند (F).

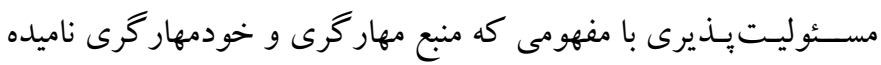

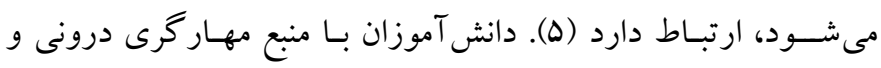

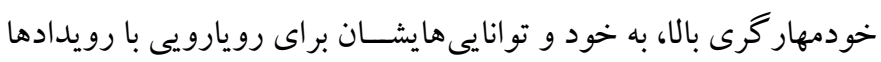

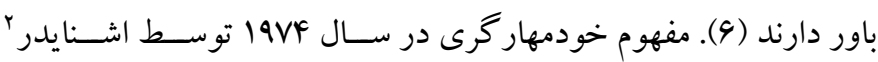

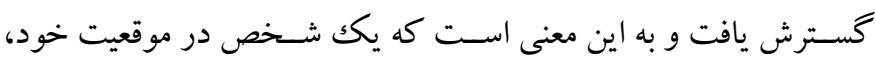

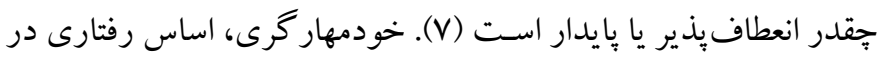
دستيابى به اهداف و اجتناب از تكانه هاى منفى است (N).

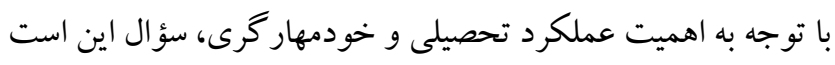
كه اضطراب به ويزٔه اضطر اب امتحان جه نقشى در اين ميان ايفا مى كند.

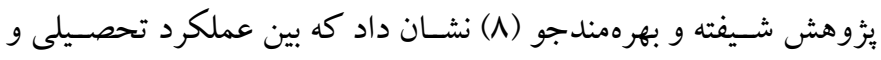

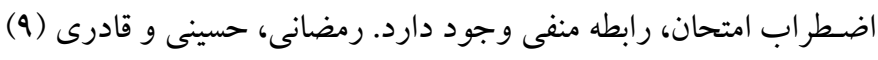

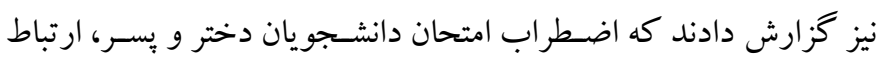

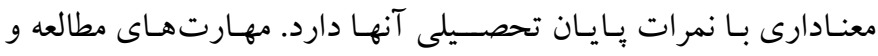

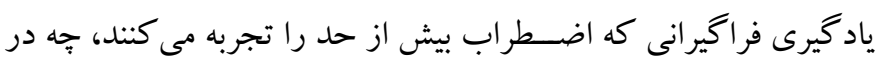


ذهن آكاهى، خودمهار گرى توجه اسـت. اوليا و سعيدمنش (II) در نشان

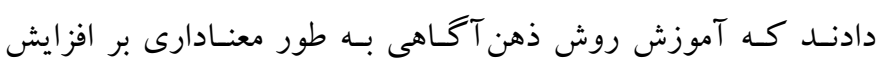

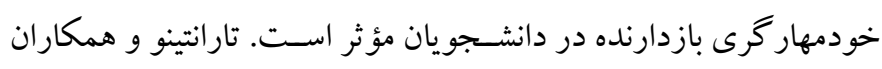

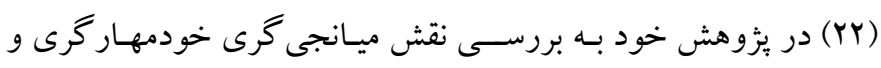

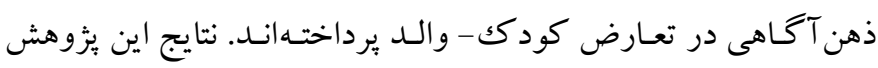

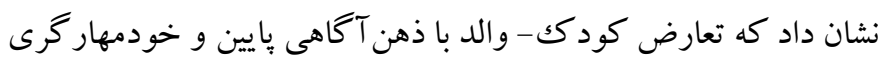

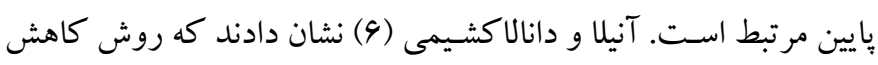

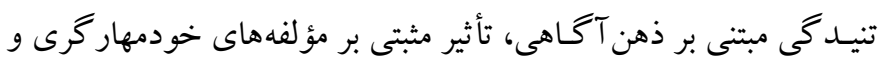

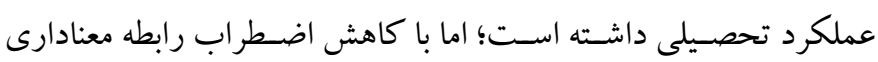

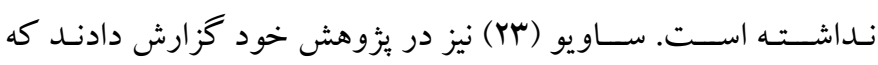
روى آورد ذهن آكاهى در كاهش اضـطر اب امتحان نقش سـازنده دارد.

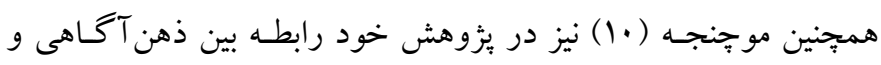

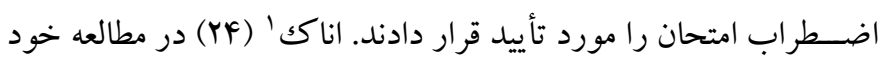

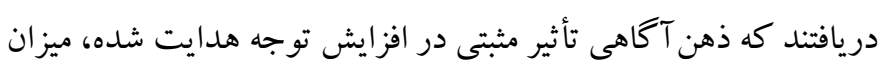

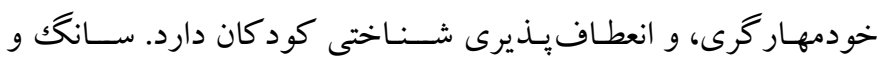

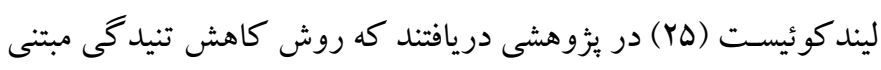

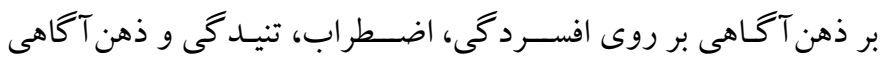
دانشجويان برستارى، اثر معنادار داشته است.

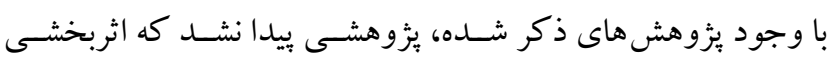

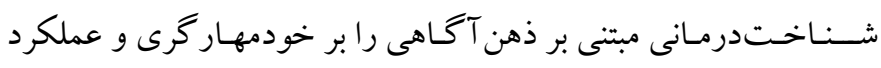

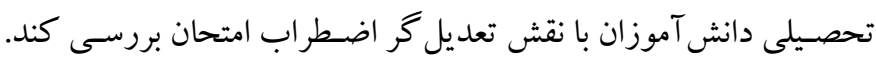

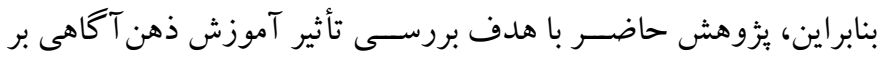

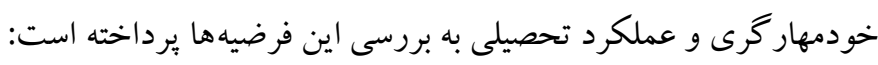

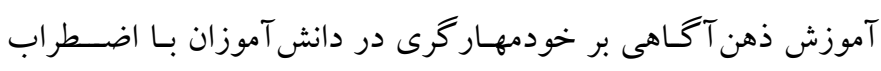

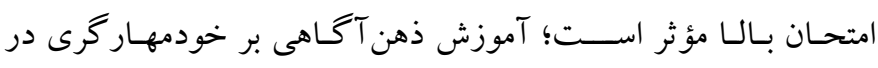

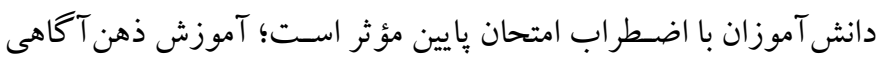

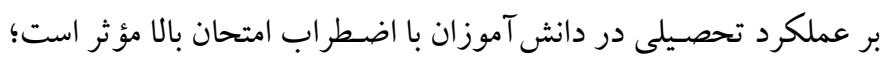

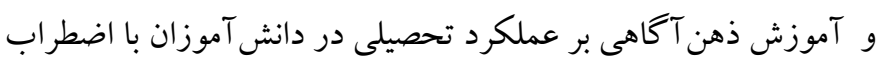
امتحان بايين مؤثر است.
ديـالكتيكك، درمـان مبتنى بر يـــيرش و تعهـد، نمونههايى از اين تلاشها

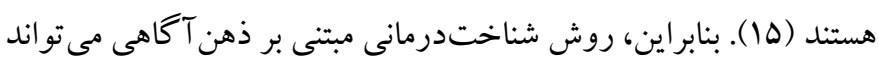

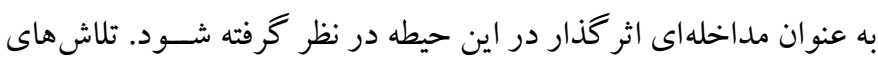

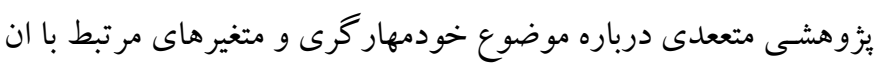

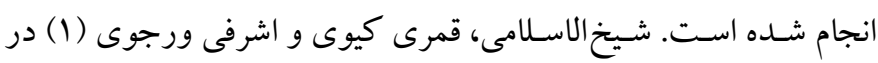

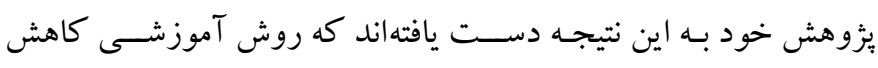
تنيـدگى مبتنى بر ذهن آكاهى بر خودمهار گرى دانش آموزان تأثير دارد.

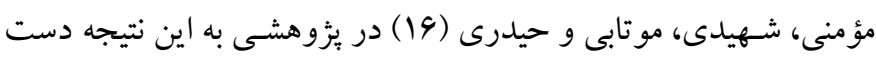

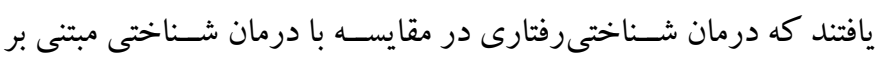
ذهن آكاهى، اثربخشى بيشترى در كاهش اجتناب شناختى و بهبود تنظيم

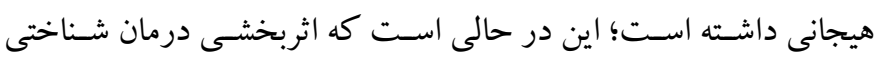

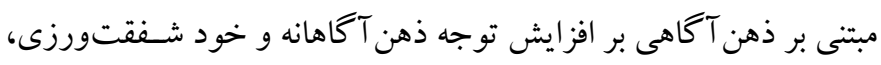

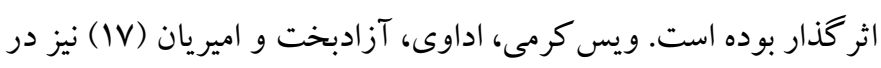

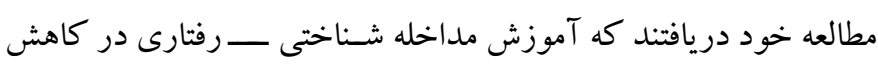

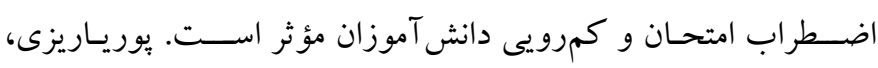

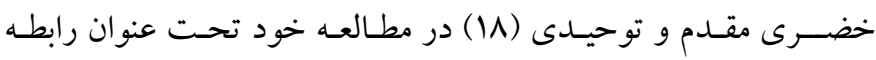

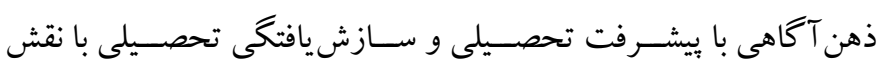

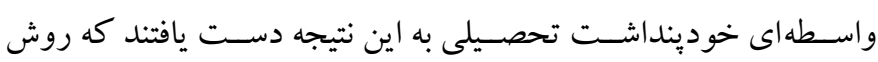

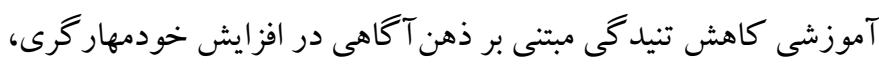
يـــيرش كمكك طلبى، و نيز كاهش اجتناب از كمكك طلبى دانش آموزان

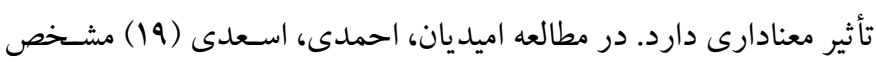

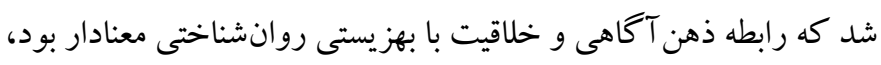
ولى رابطه مستقيم عملكرد تحصـيلى با مشـكلات روانشـناختى معنى دار

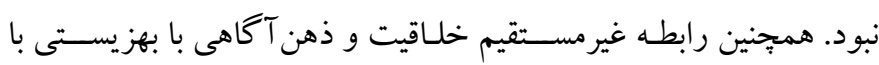
ميانجى گرى مشـكلات روانشــناختى معنادار بود؛ اما رابطه غير مســتقيم عملكرد با بهزيستى با ميانجى مشكلات روانشناختى معنادار نبود.

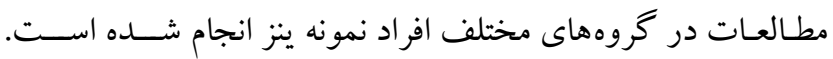

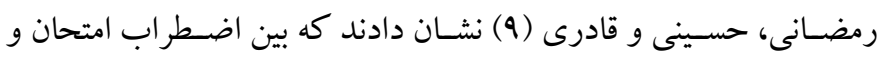

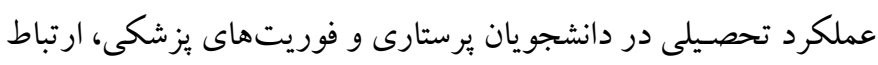

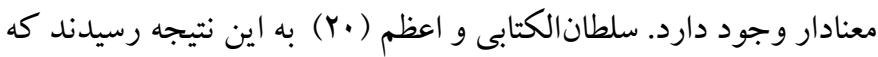

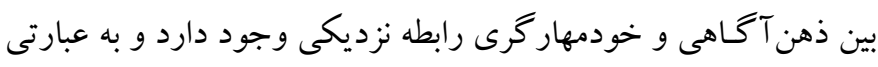

1. Enoch 


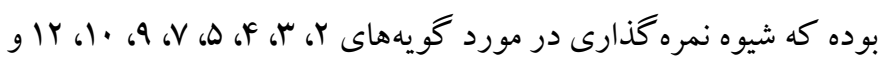
روش سا به صورت معكوس است. براى به دست آوردن امتياز كلى برسشنامه،

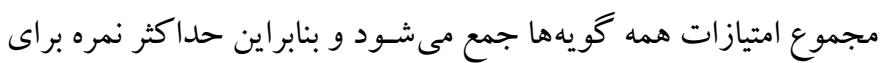

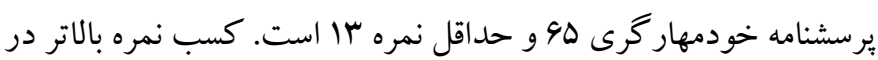

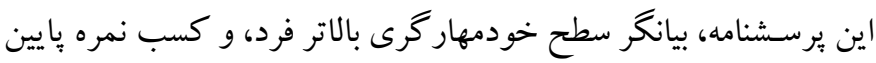

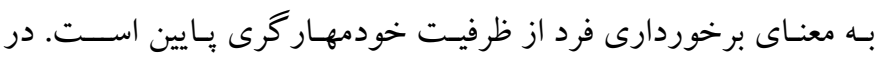

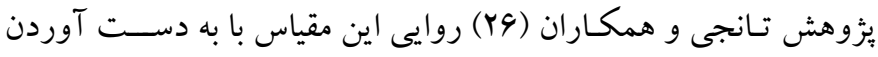

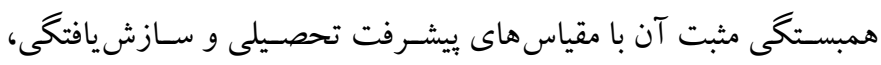

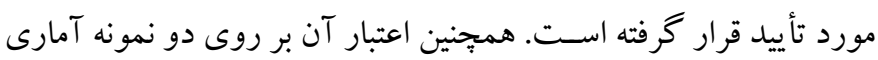

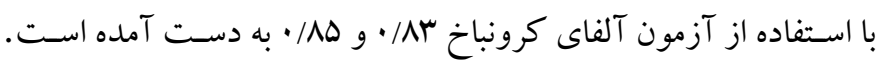

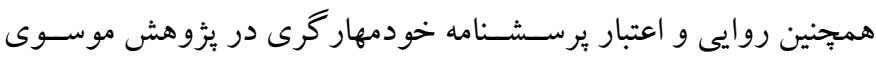
مقدم و همكاران (YV) محاسبه و مورد تأييد قرار كرفته است.

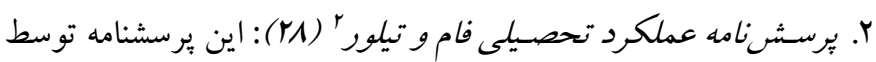

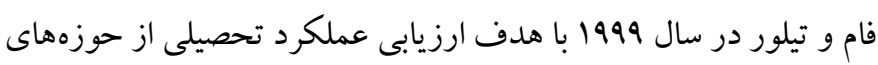

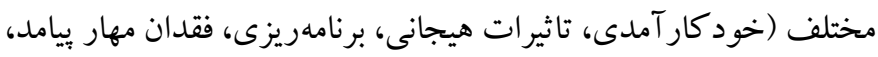

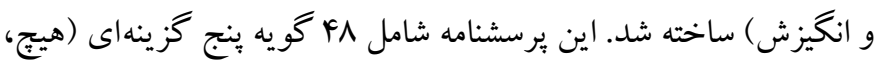
كم، تا حدى، زياد، خيلى زياد) اســكه به هر ززينه به ترتيب امتيازات .

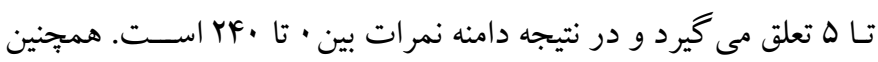

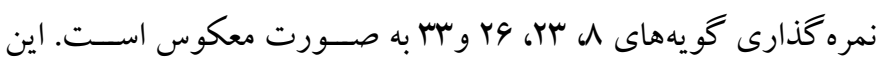

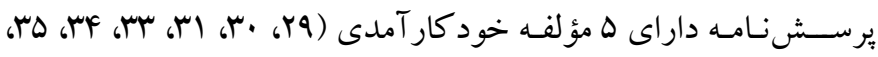

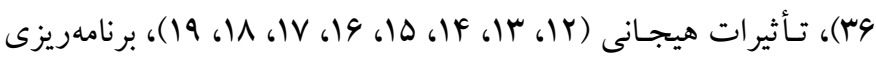

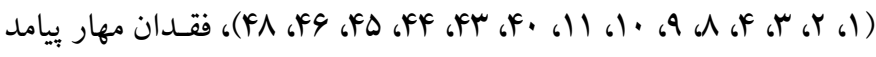

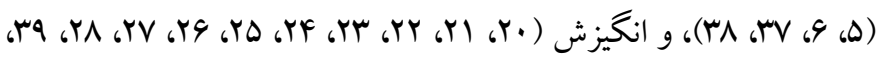

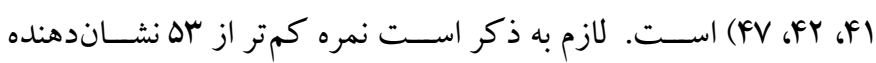

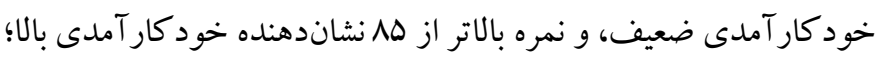

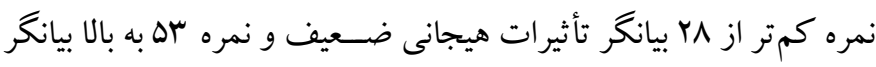

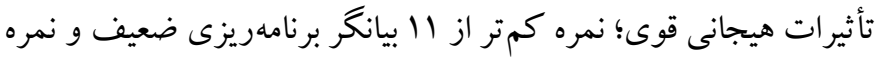

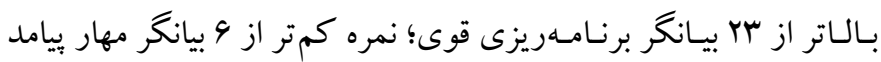

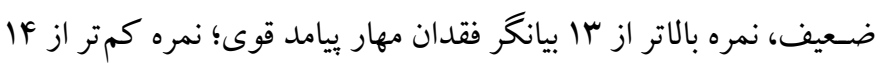

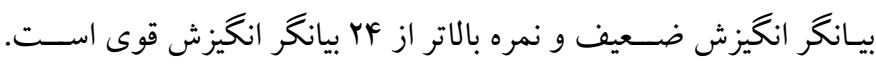

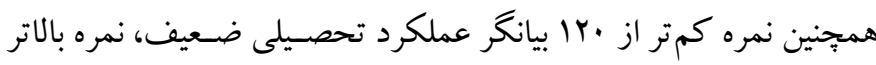


نيست كه با عملكرد امتحان تداخل كند؛ بلكه تر كيبى از نمرههاى نخر انى

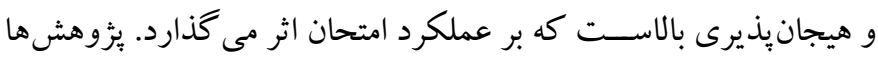

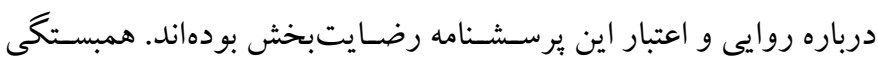

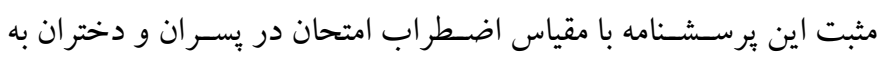

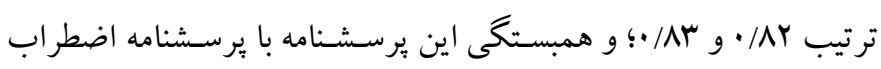

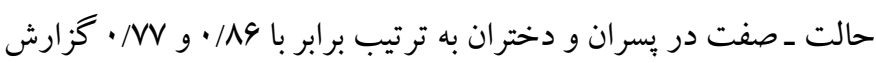

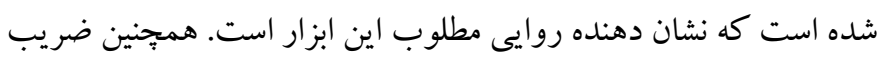

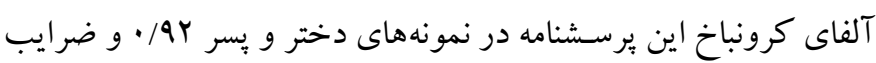

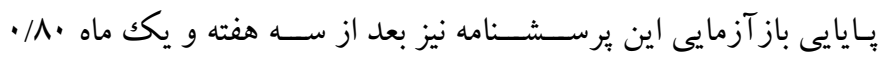

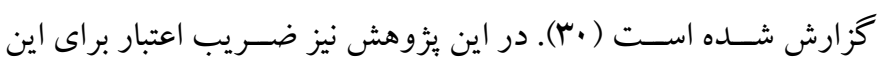

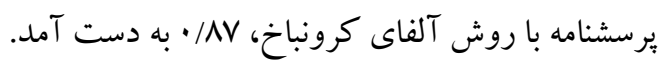

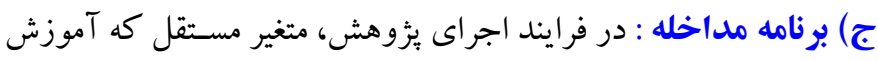

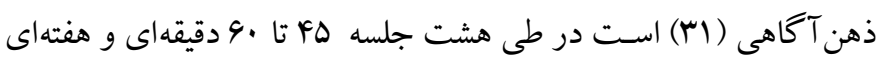

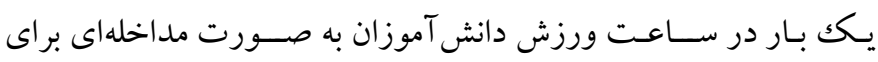

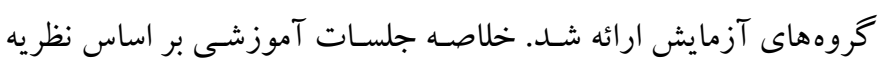

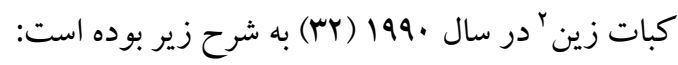

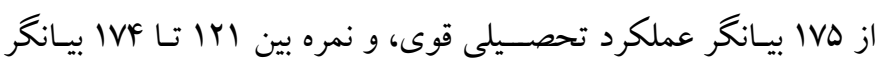

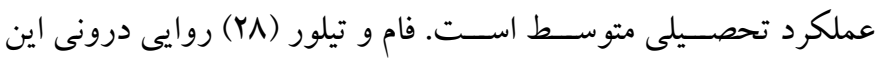

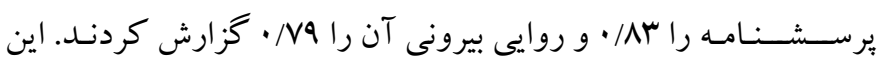

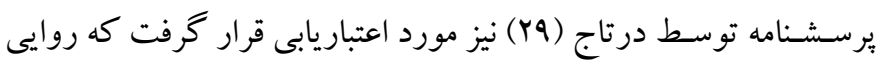

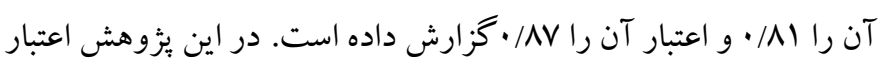
يرسشنامه به روش آلفاى كرونباخ محاسبه شد كه ضريب آلفاى كرونباخ

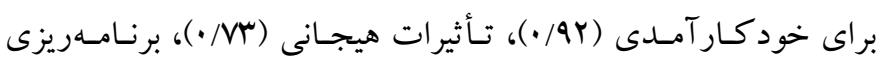

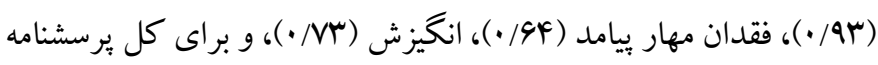
بر آورد شد. (•/VF)

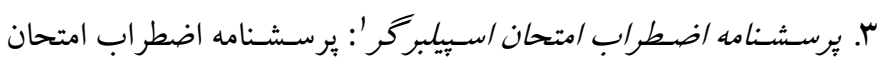

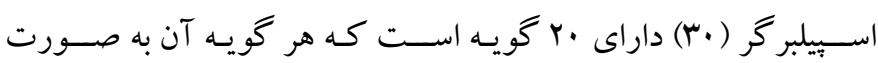

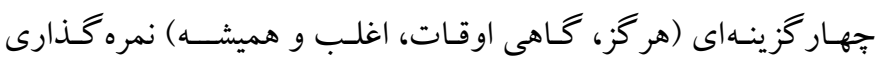

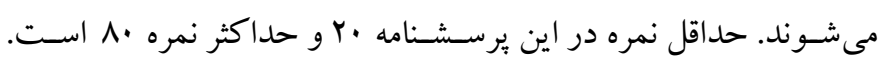

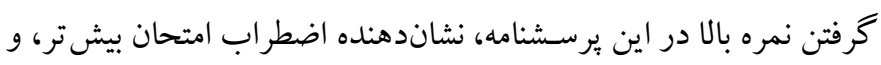

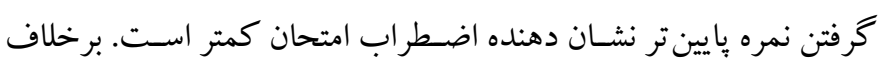

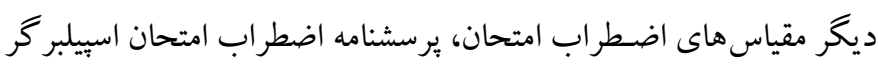

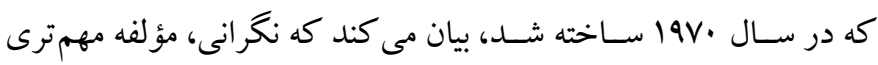

جدول r: شرح جلسات برنامه آموزش ذهن آكاهى

\section{موضوعات مورد نظر}

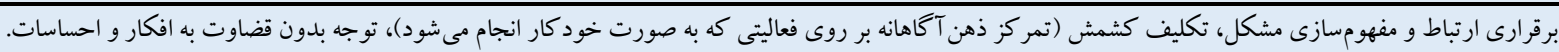

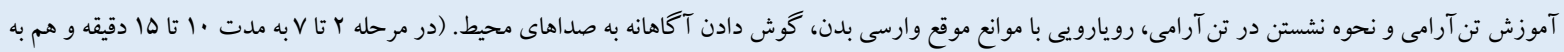

$$
\text { صورت تكليف خانگیى در هر هفته) }
$$

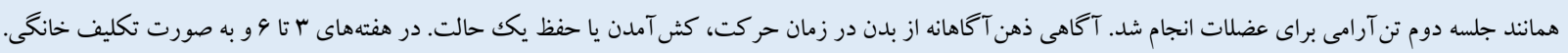

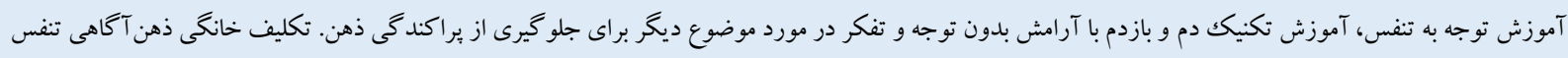

$$
\text { قبل از خواب . ب دقيقه. }
$$

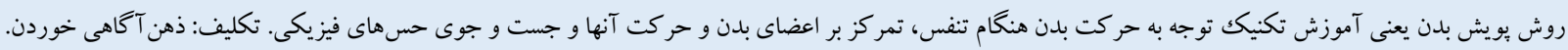

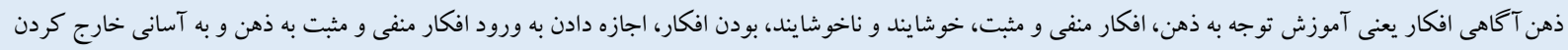

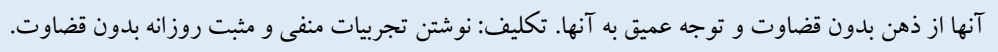

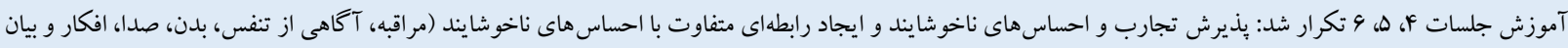

$$
\text { دشو ارىهايى كه طى تمرين روى مىدهد). }
$$

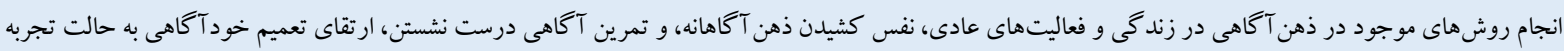

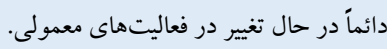

جلسات آموزشى

1

r

\section{r}

f

$\Delta$

9

V

$\wedge$ 
(اصـل رازدارى) و مى توانــد در هر مرحله از فرايند يُزوهش از جريان

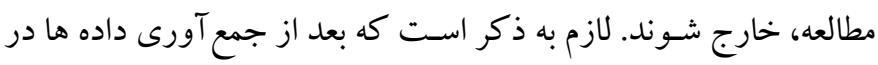

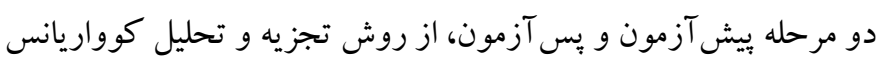
دوراهه براى آزمون فرضها مها استفاده شد.

يافتهها ميانخين و انحر اف اسـتاندارد نمرات بيش آزمون- بـ بس آزمون متغيرهاى

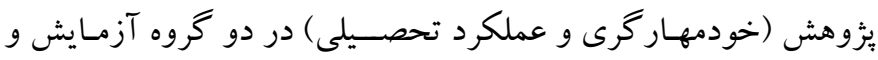

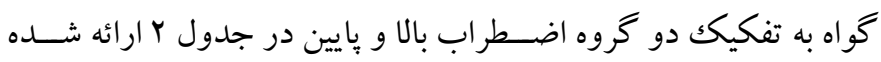

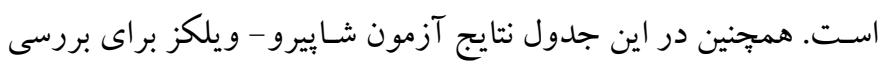

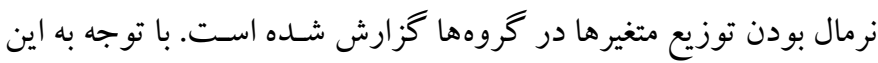

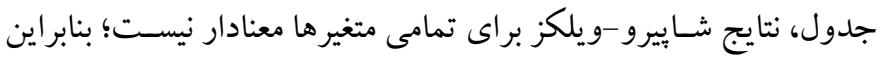

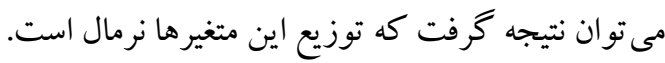

د) روش اجرا: براى اجراى اين مطـالعهـ بعـد از اخـــ مجوزهـاى لازم به

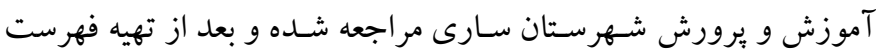

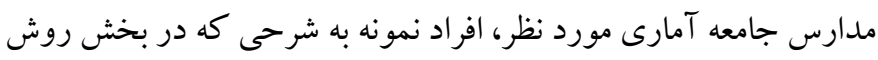
نمونه گيرى ذكر شد، به صورت خوشهاى انتخاب شدهاند. برس مشنامههاى

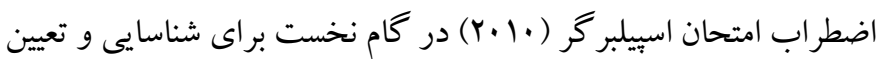

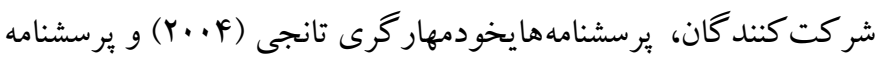
عملكرد تحصيلى فام و تيلور (1999) در گام دوم در قالب ييش آزمون به

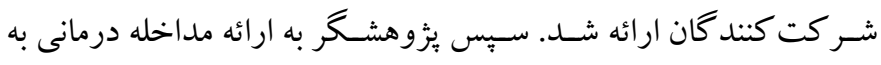
كروه آزمايش برداخت كه در قالب هشت جلسه ارائه شد. در كام نهايى،

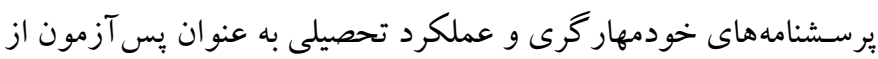

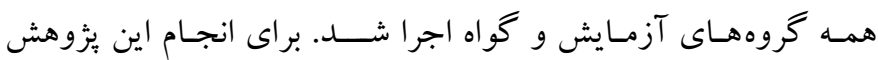

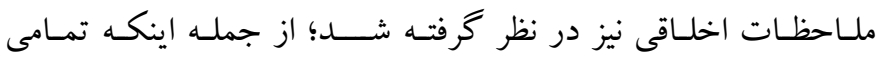

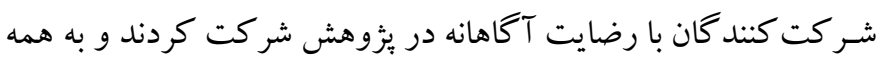

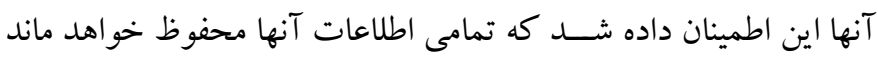

جدول ז: شاخص توصيفى نمرات ييش آزمون-يسآزمون متغير خود مهاركرى تحصيلى و عملكرد تحصيلى در كروههاى آزمايش و كواه با اضطر اب بالا و وايين

\begin{tabular}{|c|c|c|c|c|c|c|c|}
\hline $\mathbf{P}$ & شابيرو-ويلكز & انحراف استاندارد & ميانكين & كروه & وضعيت & متغير & كروه \\
\hline$\cdot / r$. &.$/ 99$ & $1 / r^{2}$ & $\wedge \Delta / \wedge$ & آزمايش & \multirow{2}{*}{ ييش آزمون } & \multirow[b]{2}{*}{ خود مهار گرى } & \multirow{8}{*}{ اضطراب بالا } \\
\hline$\cdot / \mathrm{NI}$ & $\cdot / 9 r$ & $9 / 49$ & $\Lambda \mu / .4$ & كواه & & & \\
\hline ·/va & $\cdot / 90$ & $9 / \pi$ & $1 \cdot V / 4 q$ & آزمايش & \multirow{2}{*}{ پِ آزمون } & تحصيلى & \\
\hline.$八$ & $\cdot / \wedge 9$ & $\Lambda / 9 \Delta$ & $\Delta F / I r$ & كواه & & & \\
\hline.$/$ & $\cdot / \wedge 9$ & $\mu q / \cdot \Delta$ & $\mid \cdot r / A 1$ & آزمايش & \multirow{2}{*}{ بيش آزمون } & \multirow{4}{*}{ عملكرد تحصيلى } & \\
\hline$\cdot / \mathrm{NI}$ & . /9r & $\mu F / A$. & $1.1 / 9$ & كواه & & & \\
\hline$\cdot / v \Delta$ & $\cdot / 9 \Delta$ & $M F / F G$ & $1 \cdot \Delta / A V$ & آزمايش & \multirow{2}{*}{ يس آزمون } & & \\
\hline$\cdot / 19$ & $\cdot / 19$ & $r \Delta / I r$ & $1 \cdot r / r$. & كواه & & & \\
\hline . / & $\cdot / M$ & $N / \cdot r$ & NQ/Or & آزمايش & \multirow{2}{*}{ ييش آزمون } & \multirow{4}{*}{ خود مهارگرى } & \multirow{8}{*}{ اضطر اب بايين } \\
\hline$\cdot / v$ &.$/ 91$ & V/Dr & (N/Ir & كواه & & & \\
\hline$\cdot / T F$ &.$/ 9$ & G/VF & $\Lambda \Delta / \cdot 1$ & آزمايش & \multirow{2}{*}{ يس آزمون } & & \\
\hline$\cdot / 19$ & $\cdot / \wedge 9$ & $V / \Delta$. & $\Lambda F / \cdot 1$ & كواه & & & \\
\hline$\cdot / 19$ & $\cdot / M$ & rY/AS & $1 \cdot r / A V$ & آزمايش & \multirow{2}{*}{ يِيش آزمون } & \multirow{4}{*}{ عملكرد تحصيلى } & \\
\hline .1 .9 & $\cdot / \wedge 9$ & rr/vg & $1 \cdots / 9 \mathrm{~V}$ & كواه & & & \\
\hline$\cdot / \Delta 9$ & $\cdot / 9 F$ & $10 / \mathrm{A}$ & r & آزمايش & \multirow{2}{*}{ يس آزمون } & & \\
\hline$\cdot / \cdot v$ & $\cdot / \wedge \Delta$ & $\Gamma Y / \Lambda \Delta$ & 1.r/or & كواه & & & \\
\hline
\end{tabular}

شـيب ركرسيون بيش آزمون و بس آزمون در دو متغير خودمهار گرى و

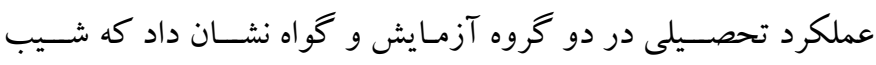

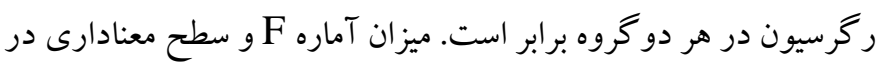

براى بررسسى تأثير آموزش ذهن آكاهى بر خودمهارگرى و عملكرد

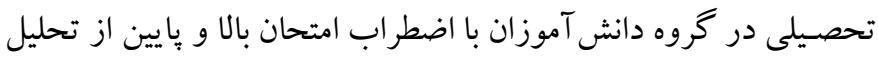

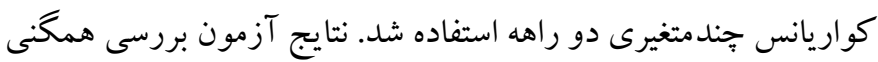


بـارتـلـت براى بررسـى كرويست يـا معنـادارى را بطـه بين دو متغير

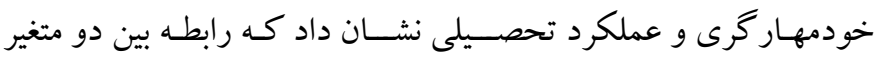

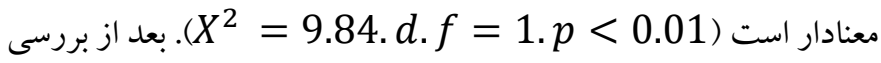
مفروضهها، نتايج تحليل كوواريانس جندمتغيرى نشان داد كه تفاوت بين

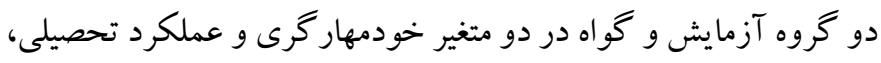
معنـادار اسـت؛ يعنى اثر آموزش ذهن آكَاهى بر تركيب خطى دو دو متهير

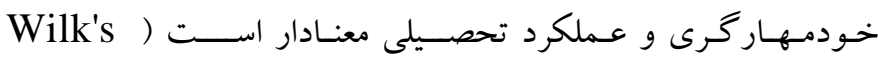
. $\left(\mathrm{Lambda}=0.42, \mathrm{~F}_{(2,53)}=35.67, \mathrm{P}<0.01\right.$

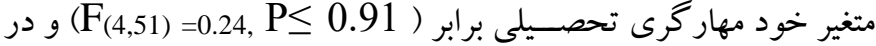

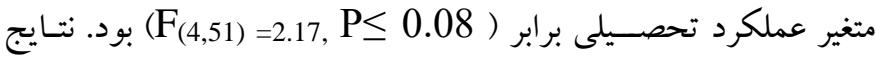

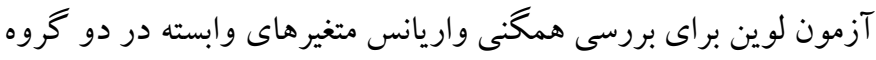

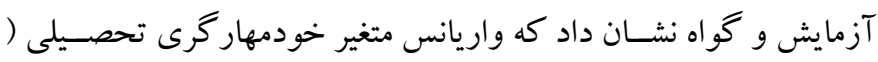

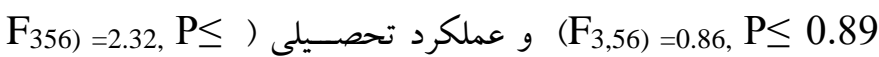

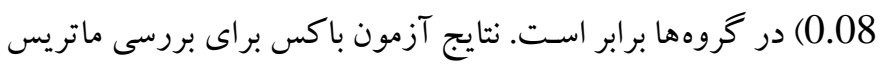

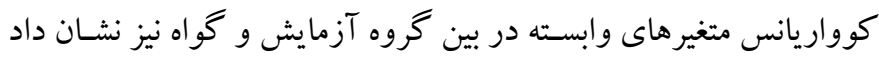

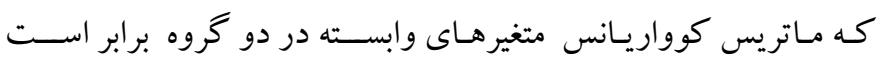

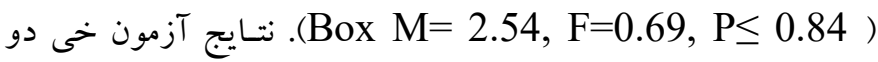

جدول س: نتايج تحليل كوارايانس تكمتغيرى در متن تحليل كوواريانس جندمتغيرى براى تأثير آموزش ذهن آكاهى بر خودمهاركرى تحصيلى و عملكرد تحصيلى

\begin{tabular}{|c|c|c|c|c|c|c|c|}
\hline اندازه اثر & $\mathbf{P}$ & $\mathbf{F}$ & ميانكين مجذورات & درجه آزادى & مجذورع مجموات & متغير وابسته & منابع تغيير \\
\hline .194 &.$/ .1$ & IV/AV & $991 / 9 F$ & 1 & $991 / 94$ & خودمهار گرى تحصيلى & \multirow{2}{*}{ ي يش آزمون } \\
\hline$\cdot / V^{F}$ &.$/ \cdots 1$ & TY/FD & $I F V / \Delta Y$ & 1 & IFV/Or & عملكرد تحصيلى & \\
\hline$\cdot / \Delta 9$ &.$/ .1$ & $\mid \mathrm{i} / \cdot \mathrm{V}$ & $10 r q / 94$ & 1 & $1 \Delta r g / 9 r$ & خودمهارگرى تحصيلى & \multirow{2}{*}{ عضويت گروهى } \\
\hline$\cdot / \cdot \wedge$ & $\cdot / \wedge$ & .1 .9 & $\cdot / k T$ & 1 & $\cdot / 4 \pi$ & عملكرد تحصيلى & \\
\hline$\cdot / 4 q$ & $\% / \cdot 1$ & $\mu \mathrm{r} / .9$ & $11 \% r / \wedge 9$ & 1 & $11 \% r / \wedge 9$ & خودمهارگرى تحصيلى & \multirow{2}{*}{ نوع اضطراب } \\
\hline$\cdot / f F$ & $\cdot / \cdot 1$ & rN/GY & G4Q/AG & 1 & $q \notin \Delta / \wedge q$ & عملكرد تحصيلى & \\
\hline .194 &.$/ \cdot 1$ & $49 / 09$ & $V \Lambda F / \Delta \Lambda$ & 1 & $V \wedge F / \Delta \Lambda$ & خودمهار گرى تحصيلى & \multirow{2}{*}{ عضويت گروهى"نوع اضطراب } \\
\hline$\cdot / \mu q$ & $\cdot / \cdot 1$ & $r Y / Y)$ & $\Delta F F / Y F$ & 1 & $\Delta F F / Y F$ & عملكرد تحصيلى & \\
\hline & & & $r V / F r$ & $\Delta F$ & $1 \cdot 1 \cdot / \Delta r$ & خودمهار گرى تحصيلى & \multirow{2}{*}{ خطا } \\
\hline & & & rT/DQ & $\Delta F$ & $9 \cdot 9 / 41$ & عملكرد تحصيلى & \\
\hline
\end{tabular}

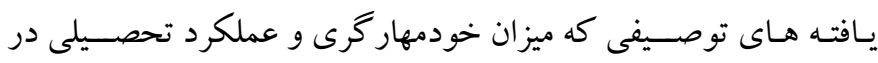

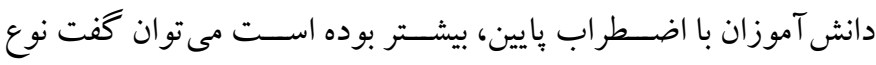

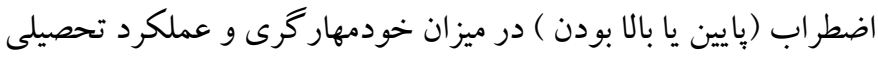

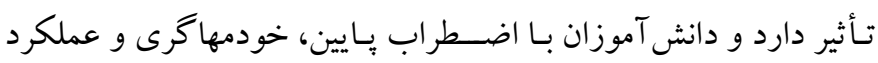

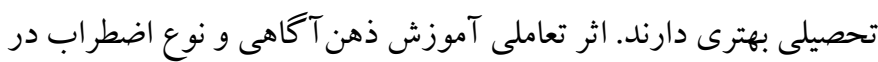

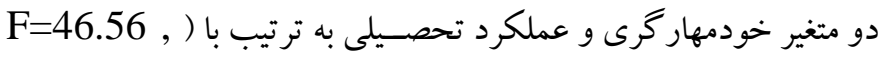
اضط اضـطراب، تأثير آموزش ذهن آكَاهى را بر ميزان خودمهـاركرى و

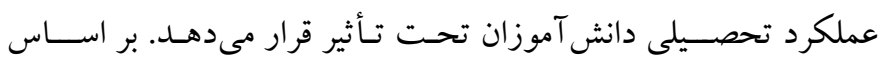

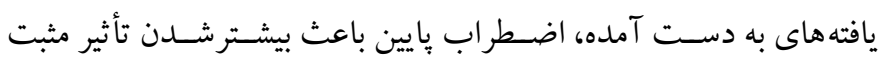

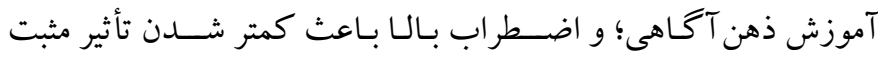

بر اســاس جـدول با، نتـايج تحليـل كواريـانس تككمتغيرى در متن

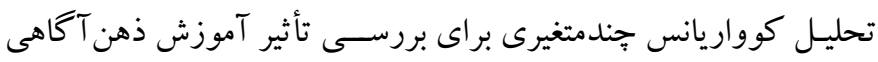

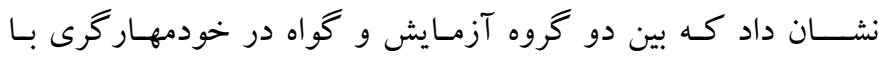
(F=41.07, P<0.01) دارد و در متغير عملكرد تحصيلى با (F=0.06, P>0.05) بين دو گرووه

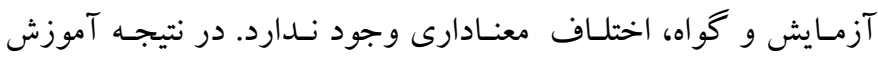
ذهن آكاهى در افزايش خودمهارگرى تحصسيلى دانش آموزان مؤثر بوده

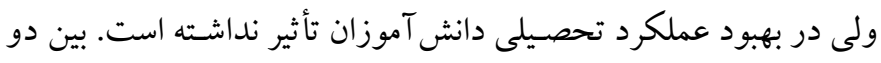

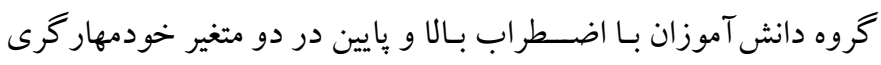

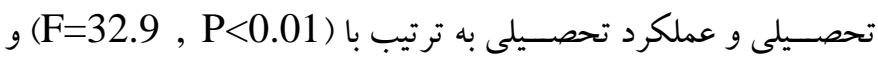

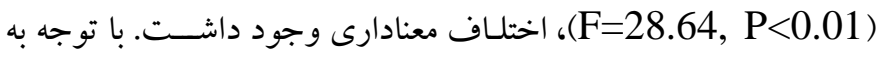




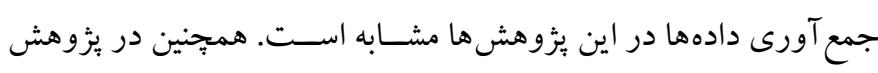

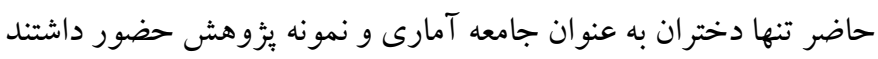

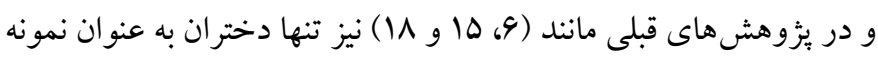

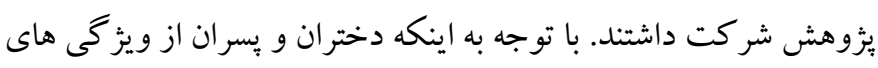

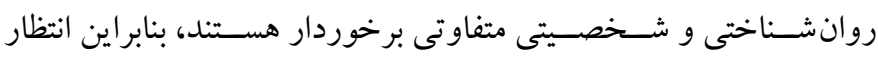

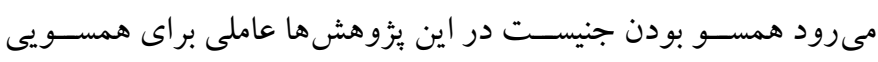
يافتها باشد. يافتها همجِنين نشان داد كه آموزش ذهن آكاهى بر خودمهار گرى و

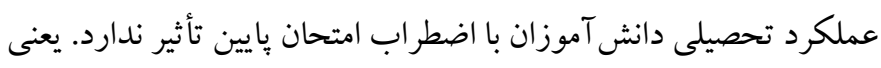

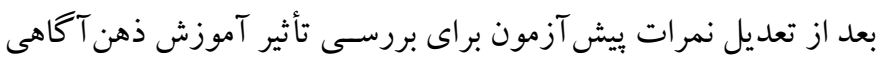

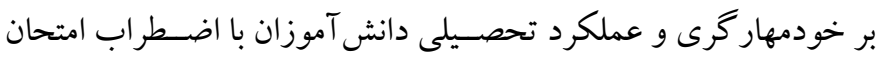

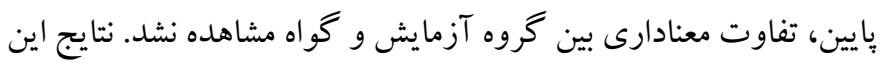

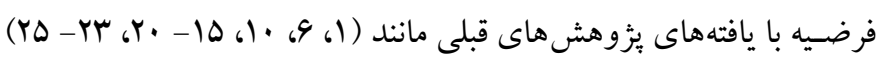

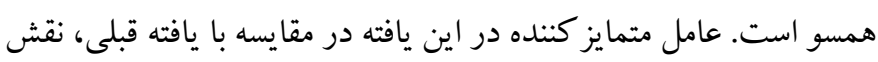

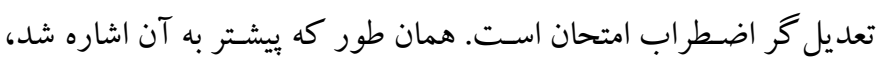

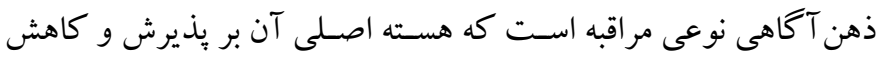

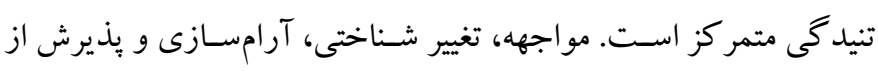

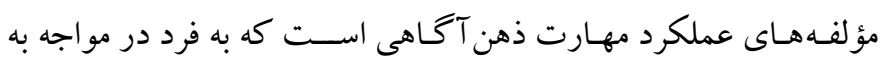

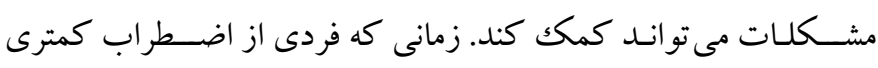
برخوردار اسـت؛ اين خود نشـاندهنده مؤلفه هاى مواجهه، تغيير شناختى،

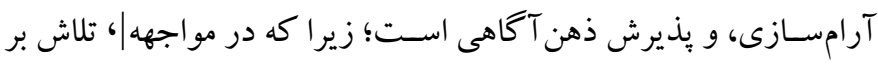

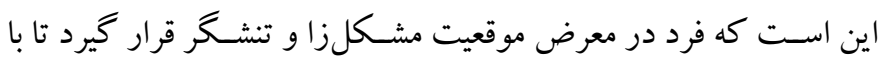

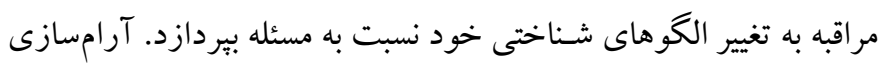

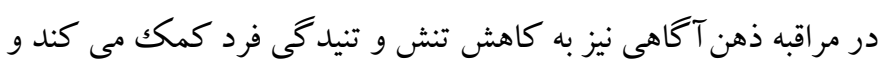

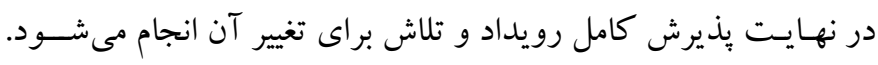
افر ادى كه اضطر اب كمترى دارند، در مواجهه با موقعيت مشكلز الها، بهتر عمل مى كنند؛ قادرند الكوى شناختى مناسب و اثربخشى نسبت به مسئله

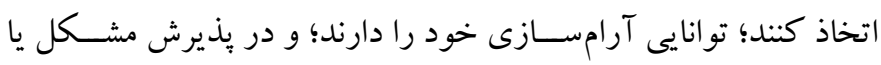

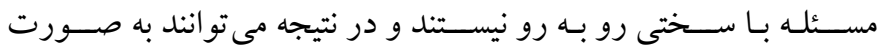

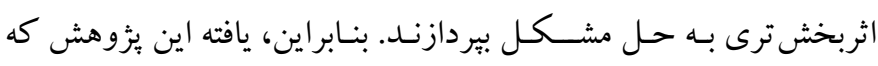

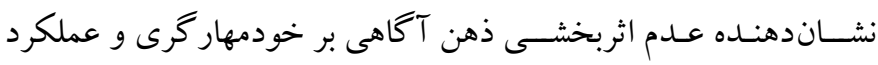

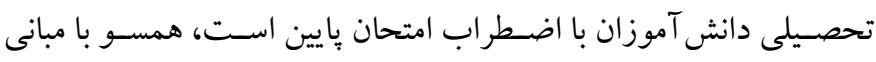

آمـوزش ذهن آكـاهى در بهيود خودمهـاركرى و عملكرد تحصـيلى

$$
\text { دانش آموزان مى دود. }
$$

\section{بحث و نتيجه Fيرى}

اين يزوهش با هدف بررسى تأثير شناخت درمانى مبتنى بر ذهن آكاهى برى

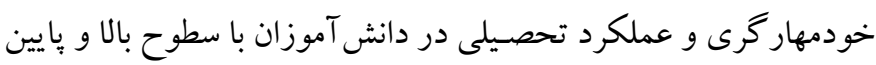

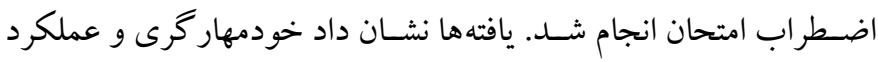

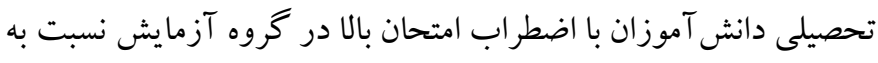

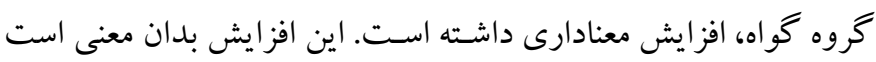

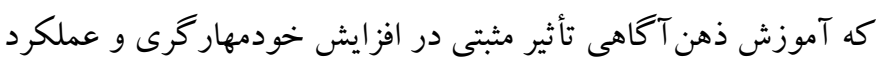

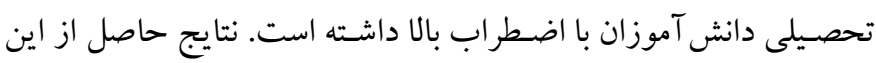

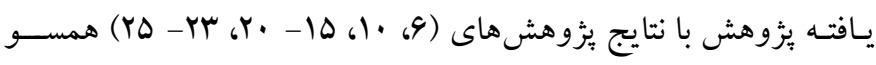

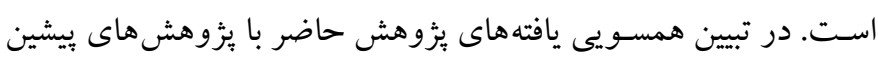

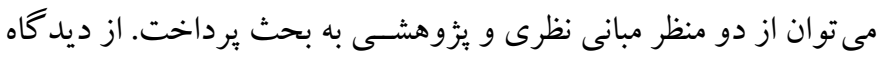

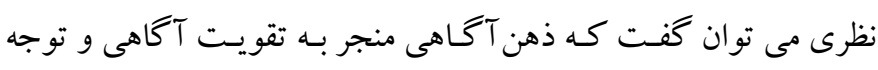

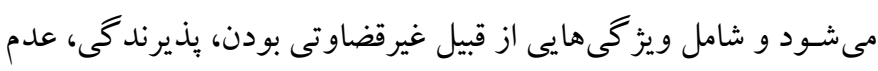

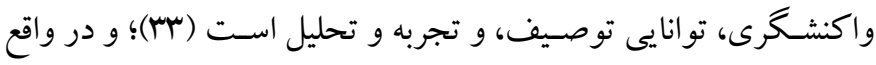

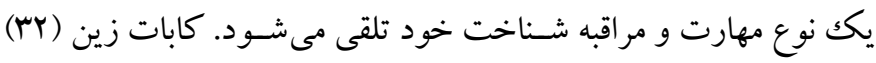
بيان مى كند كه مهارت ذهن آكاهى مكانيسم مواجه، تغيير شناختى، اداره

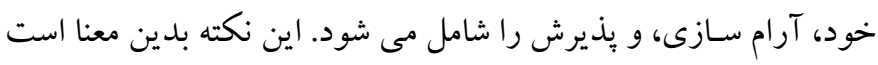

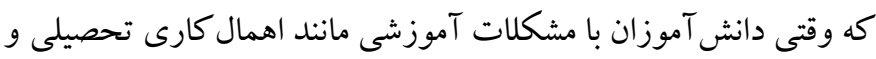

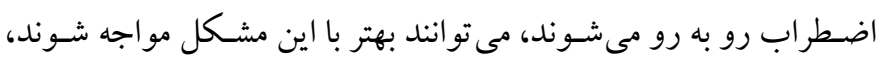
الكوى شناختى خود نسبت به مشكل را تغيير مثبت دهند، به مهار و اداره خود بيردازد و با آرامسـازى و يذيرش، به مقابله مؤثر با مشـكل بيردازند.

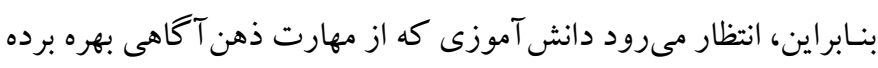

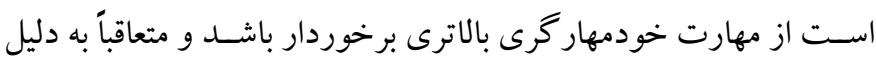

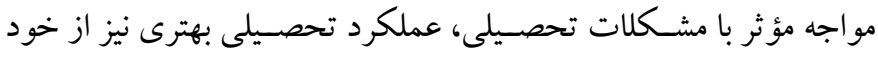

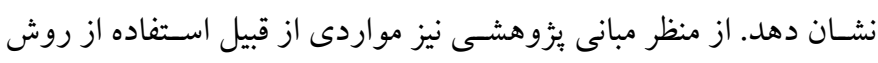

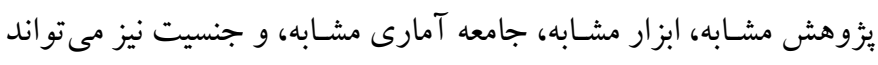

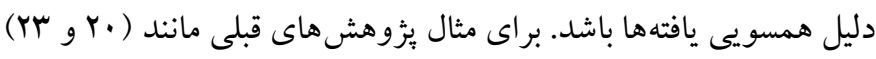

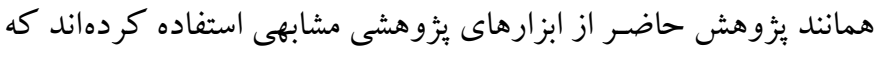

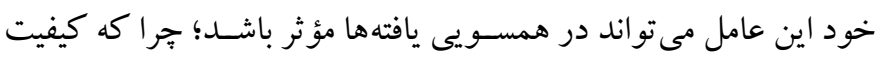


براى افزايش اين دو مورد در دانش آموزان بـا اضـطراب يـايين جارهاى

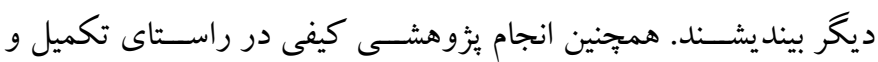
يشــيبانى از نتايج اين يزوهش در قالب مطالعات موردى، مصــاحبه هاى

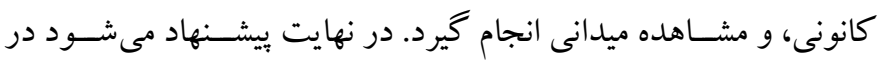

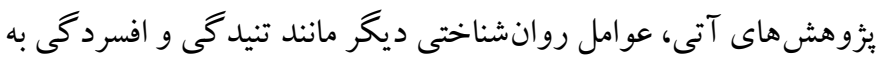
عنوان متغير تعديل گر در نظر گرفته شوند.

تشــكر و قدردانى: اين مطالعه به صــورت مسـتقل اجرا شـــه و بركرفته از پايانامه يا طرح يُزوهشى نيست. همجنين مجوز اجراى آن بر روى افراد نمونه

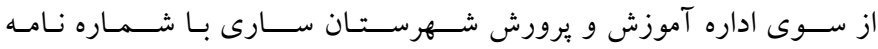

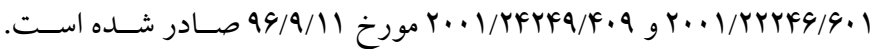

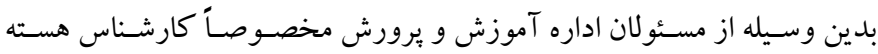

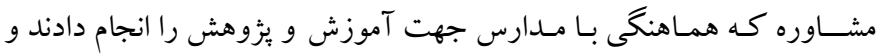

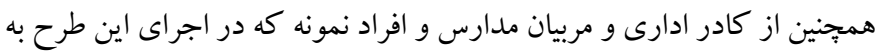
ما كمك كردند، تشكر و قدردانى مى شود. تضاد منافع: اين يُزوهش براى نويسند كان هيج گونه تضاد منافع نداشته است.
نظرى و مطـالعات قبلى اسـت. در كل مىتوان جنين نتيجه كرفت كه با توجه به آسيب ها و نابهنجارى هاى مربوط به بايين بودن خودمهار گرى و و

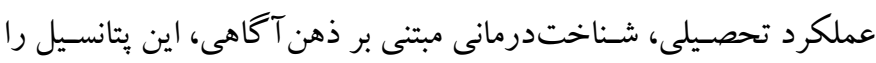

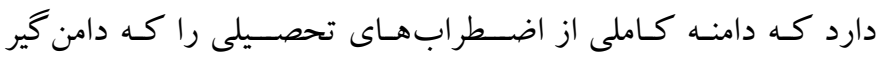

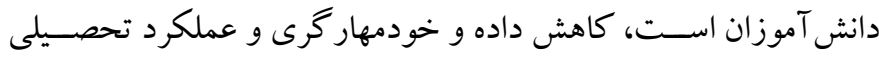
آنها را افزايش دهد. از محسدوديـتهــاى اين بزروهش مى توان بـهـ محسدود بودن دامنـهـ

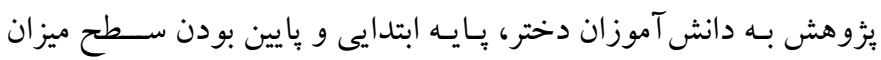

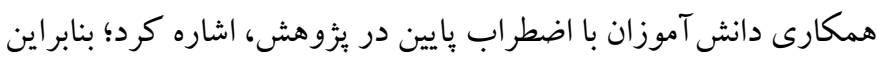

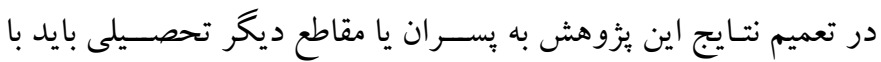

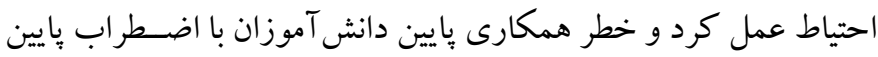

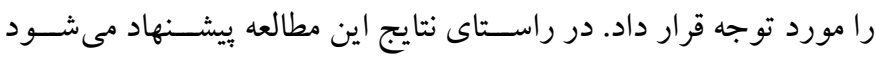

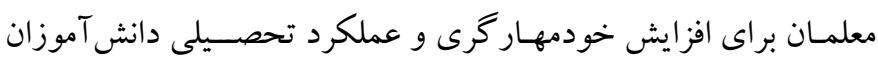
داراى اضطر اب امتحان بالا از روش ذهن آكاهى استفاده كنند و با توجه

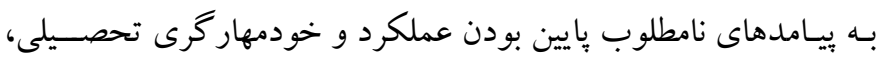




\section{References}

1. Sheykholeslami A. Ghamari Kivi H, Ashrafi Vorjoi S. The effect of knowledge-based learning method on self-control of girl students. Quarterly Journal of Research in Educational Systems. 2016; 9(28): 87104. [Persian]. [Link]

2. Moshtaghiyan M. Comparison of students' academic performance: boarding schools with day schools. Qaemshahr: Yasna Scientific Publications; 2015, pp: 108 [Persian]. [Link]

3. Hashemi R, Mohammadzade J, Hatefi M. A mediator role of self-control in relation of the attachment styles and angry in high school female students of Ilam. Scientific Journal of Ilam University of Medical Sciences. 2018; 25(5): 170-179. [Persian]. [Link]

4. DeLisi M. Low self-control is a brain-based disorder. In: Beaver KM, Barnes JC, Boutwell BB, editor. The nurture versus biosocial debate in criminology: on the origins of criminal behavior and criminality. SAGE Publications; 2014, pp: 172-184. [Link]

5. Yusainy C, Lawrence C. Relating mindfulness and self-control to harm to the self and to others. Pers Individ Dif. 2014; 64: 78-83. [Link]

6. Anila MM, Dhanalakshmi D. Mindfulness based stress reduction for reducing anxiety, enhancing self-control and improving academic performance among adolescent students. Indian Journal of Positive Psychology. 2016; 7(4): 390-397. [Link]

7. Lesani A, Shahbazi M. The effect of self-controlled practice on basketball free throw performance and self-efficacy of female students. Sport Psychology Studies. 2017; 6(21): 61-76. [Persian]. [Link]

8. Shifteh A, Bahremandjou S. Prediction of academic performance and anxiety in adolescents' exams based on parenting styles and parental intimacy. The Journal of New Advances in Behavioral Sciences. 2017; 2(13): 14-30. [Persian]. [Link]

9. Ramezani J, Hossaini M, Ghaderi MR. The relationship between test anxiety and academic performance of nursing and emergency medical technician students. Education Strategies in Medical Sciences. 2016; 9(5): 392-399. [Persian]. [Link]

10. Muchenje KM. Associations between mindfulness and test anxiety in community college students [Doctoral dissertation]. [Minnesota, United States]: Capella University; 2016, pp: 34-45 [Link]

11. Pornaghash tehrani, S., Fadavi, E., Nasri, M. (2017). Predicting academic performance in terms of selfconcept, self-esteem and self-control in elementary students. Journal of Developmental Psychology. 6 (2). 99-111. (Persian) [link]

12. Arab Ghaeni M, Hashemian K, Mojtabaei M, Majd Ara E, Aghabeiki A. The effect of mindfulness training (MBSR) on the increasing assertiveness among anxious students. Urmia medical journal. 2017; 28(2): 119-129. [Persian]. [Link]

13. Stein SD. Impact of a 3-minute mindfulness-based exercise on anxiety and academic performance [Doctoral dissertation]. [Cincinnati, Ohio, United States]: Union Institute and University; 2016, pp: 2133. [Link]

14. Maynard BR, Solis MR, Miller VL, Brendel KE. Mindfulness-based interventions for improving cognition, academic achievement, behavior, and socioemotional functioning of primary and secondary school students. Campbell systematic reviews 2017:5. Campbell Collaboration; 2017. [Link]

15. Ghasemi R. The effectiveness of mindfulness education in reducing marital burning of addicted wives women [Master's Thesis]. [Tehran, Iran]: Faculty of Psychology and Educational Sciences, Kharazmi University of Tehran; 2015, pp: [Persian]. [Link]

16. Momeni F, Shahidi S, Mootabi F, Heidari M. Comparison of the effectiveness between cognitive behavior therapy and mindfulness based cognitive therapy in mediator variables of generalized anxiety disorder. Journal of Applied Psychological Research. 2017; 8(1): 49-66. [Persian]. [Link]

17. Veiskarami HA, Adavi H, Azadbakht Z, Amairian L. Effectiveness of cognitive-behavioral intervention training in decreasing the students test anxiety and shyness. Journal of Applied Psychological Research. 2017; 8(3): 29-45. [Persian]. [Link]

18. Abyar, Z., Makvandi, B., Bakhtiyarpour,S., Naderi, F., Hafezi,F. (2018). Comparison of the Effectiveness of Acceptance and Commitment, Mindfulness, and Combined Therapy (Mindfulness, Commitment, and Acceptance) on Depression. Journal of Child Mental Health. 4(17). 27-38. [Persian] [Link]

19. Omidian M, Ahmadi S, Asadi S. The role of creativity, mindfulness and academic performance on well-being: with mediating role of psychological problems. Journal of Psychological Achievements. 2017; 24(2): 101-116. [Persian]. [Link]

20. Shamli, M., Motamedi,A., Borjali, A. (2018). The Effectiveness of Mindfulness-Based Cognitive Therapy on Internet Games Addiction by Mediating Self-Control and Emotion-seeking Variables in 
Tehran's Male Adolescents. Counseling and Psychotherapy Culture. 9(33). 137-161. (Persian) [Link]

21. Tajodini, S., Tohidi, A., Mousavinasab, H. (2018). The Effect of Mindfulness-Based Stress Reduction Training on Academic Performance, Academic Self-Regulation and Mindfulness in High School Students. Educational Psychology Studies. 14 (31). 59-88. [Link]

22. Tarantino, N., Lamis, D. A., Ballard, E. D., Masuda, A., \& Dvorak, R. D. (2015). Parent-child conflict and drug use in college women: A moderated mediation model of self-control and mindfulness. Journal of counseling psychology, 62(2), 303 [Link]

23. Savoie SJ. A brief mindfulness approach to reducing test anxiety: using an environmental cue to signal mindfulness during an evaluative situation [Master's thesis]. [Louisiana, United States]: University of Louisiana at Lafayette; 2016, pp: [Link]

24. Enoch M. Using mindfulness to increase directed attention, self-control, and psychological flexibility in children [PhD thesis]. [Illinois, United States]: Southern Illinois University Carbondale; 2015. [Link]

25. Song Y, Lindquist R. Effects of mindfulness-based stress reduction on depression, anxiety, stress and mindfulness in Korean nursing students. Nurse Educ Today. 2015; 35(1): 86-90. [Link]

26. Tangney, J., Baumeister, R. F., \& Boone, A. L. (2004). High self-control predicts good adjustment, less pathology, better grades, and interpersonal success. Journal of Personality, 72, 271-324. [Link]

27. Mousavi Moghadam, S, R. (2015). The Relationship between Spiritual Intelligence with Self-Control and Defense Mechanisms in Third Year High School Girl Students. Journal of Islamic Azad University of Medical Sciences, 25 (1), 59-64. [Link]
28. Pham LB, Taylor SE. From thought to action: Effects of process-versus outcome-based mental simulations on performance. Personality and Social Psychology Bulletin. 1999 Feb; 25(2):250-60. [Link]

29. Dortaj F. Investigating the effect of process and process mental simulation on improving academic performance of students. Making standardization of academic performance test $[\mathrm{PhD}$ Thesis]. [Tehran, Iran]: Faculty of Psychology and Educational Sciences, Allameh Tabataba'i University; 2004, pp: [Persian]. [Link]

30. Spielberger CD. Test anxiety inventory. The Corsini encyclopedia of psychology. 2010 8(1):73-81. [Link]

31. Haghani Zemeydani M. The effectiveness of mindfulness education on reducing labor conflict the family of married nurses [Master's thesis]. [Tehran, Iran]: Allameh Tabataba'i University; 2016, pp: [Persian]. [Link]

32. Kabat-zinn,j. (2003). Mindfulness-based stress reduction (MBSR). Constructivism in the Human Sciences, 8(2), 73. [Link]

33. Abyar, Z., Makvandi, B., Bakhtiyarpour,S., Naderi, F., Hafezi,F. (2018). Comparison of the Effectiveness of Acceptance and Commitment, Mindfulness, and Combined Therapy (Mindfulness, Commitment, and Acceptance) on Depression. Journal of Child Mental Health. 4(17). 27-38. [Persian] [Link]

34. Abolghasemi A, Najarian B. Test anxiety, assessment and Treatment. Psychological Research. 2000; 5(3\&4): 82-99. [Persian]. [Link]

35. Crane R. Mindfulness based cognitive therapy. Khoshlahje Sedgh A (Persian translator). Publication of Be'sath; 2012, pp: [Persian]. [Link] 